\title{
Periodontal profile and oral hygiene status in pregnants at maternity hospital in the state of Goias, Brazil
}

\author{
Ricardo Natã Fonseca Silva1', Miriam Rodrigues Monteiro², Bruna Verly Grodzikwoski², \\ Fabrício Luscino Alves de Castro ${ }^{3}$, Virgílio Moreira Roriz ${ }^{4}$
}

1. Department of Stomathology (Oral Pathology), School of Dentistry, Universidade Federal de Goiás, Goiânia, GO, Brazil.

2. University Center of Anapolis - UniEVANGELICA - Anapolis (GO), Brazil

3. Paulista State University of Mesquita Filho UNESP - Araçatuba (SP), Brazil.

4. Department of Stomathology (Periodontology), School of Dentistry, Universidade Federal de Goiás, Goiânia, GO, Brazil.

* Corresponding Author: Virgílio Moreira Roriz | Federal University of Goias, School of Dentistry | Praça Universitária, $2^{\circ}$ andar. Setor Universitário. Goiânia, GO-Brasil | E-mail: vmroriz@hotmail.com | Cell phone: +55 (62) 98133-2347

Work received on 30/01/2018.

Approved for publication on 28/02/2018

\begin{abstract}
Objective: The aim of this study was to assess the periodontal status of women during pregnancy attended in a maternity hospital, as well as their oral hygiene habits. Materials and Methods: The sample was composed by 100 pregnant women, ranging from their first to ninth month of pregnancy, were examined at a maternity hospital in Goiás, Brazil. They received information about oral hygiene techniques and they were submmited a periodontal examination in a dentist's office, where the Periodontal Screening and Recording (PSR) codes were verified along with bleeding on probing and tooth loss. Results: About their pregnancy period, the most (46\%) were in their third trimester at the time of this study. The gingival index showed an average of $12 \%$ and $90 \%$ of the patients presented PSR Code 2 . As for dental hygiene, $55 \%$ reported brushing three times a day and $48 \%$ used dental floss daily. Conclusion: The most pregnant women in the third trimester, showed a prevalence for gingivitis. They reported brushing their teeth three times a day and using dental floss daily.
\end{abstract}

KEY WORDS

Pregnancy; Periodontal disease; Oral hygiene; Tooth brushing; Gingival index.

Rev. Clin. Periodoncia Implantol. Rehabil. Oral Vol. 11(3); 140-142, 2018.

\section{INTRODUCTION}

Gestation is a critical period in the female life cycle, in which a series of hormonal changes causes a woman's body to undergo various modifications. These usually include oral problems, mainly related to the periodontium ${ }^{(1,2)}$. Periodontal disease is the second most common oral disease in the world. It is a bacterial inflammation of the periodontal tissue, resulting from the accumulation of dental biofilm on the external surface of the tooth. Its occurrence is associated with poor socioeconomic conditions, difficult access to health services, and health-related behaviors involving smoking, a carbohydrate-rich diet, and poor oral hygiene $e^{(3,4,5)}$.

The gestational period demands special care of oral health, as considerable periodontal changes, such as hyperemia, edema and a marked tendency to gingival bleeding become more prevalent. A recent systematic review has shown that the periodontium, as support and sustainer, is a target tissue for estrogen and progesterone receptors, which trigger a greater hormonal concentration in the gestation period and lead to exacerbated inflammatory processes ${ }^{(5)}$. This increase results in the development or exacerbation of gingivitis gives rise to gingival granulomas and the progression of preexisting periodontitis ${ }^{(6)}$.

Research has shown that Fusobacterium nucleatum, a common oral bacterium in periodontal diseases, can invade not only periodontal cells, but also other types of cell in the human body even leading to a probable association between periodontal disease and intercurrences during pregnancy (premature birth and low birth weight $)^{(5,7)}$. An experimental study in rats has shown that maternal periodontal disease can increase the plasma concentration of the Tumor Necrosis factor-alpha and Interleukin-6, thereby allowing periodontal pathogens to reach the amniotic cavity and cause pregnancy complications ${ }^{(8)}$.

There are two main reasons for the need for buccal care during pregnancy: pregnant women need to eat properly and, for that reason, should not present pain and/or dental mobility. As well as that, periodontal infections could spread via the bloodstream and stimulate the production of inflammatory cytokines, which could accelerate the mechanisms of labor ${ }^{(9)}$.

In the first trimester of gestation there is intense cell proliferation, differentiation, and organization, and it is the most critical period for elective outpatient interventions. The third trimester also demands care, as different factors can lead to capillary stimuli and/or those associated with the autonomic nervous system, thereby influencing the moment of delivery. Thus, the second trimester of gestation is the most suitable for carrying out elective outpatient dental procedures6, because by the fourth month the greatest part of organogenesis has already been completed ${ }^{(10)}$.

Thus, it is vitally important that not only the dentist knows the buccal conditions of pregnant women, but also that each pregnant woman recognize what is normal in her mouth and know the more common changes and pathologies occurring during gestation. Minimizing the risk of pregnancy complications and the transmissibility of pathogenic oral microorganisms constitutes essential preventive behavior for both mother and baby.

This study set out to evaluate the periodontal conditions related to the gestation period, and discover the oral hygiene habits of pregnant women.

\section{MATERIALS AND METODS}

This research was approved by the Research Ethics Committee at Centro Universitário de Anápolis - UniEVANGELICA and catalogued as $460.675 / 2013$

It is an observational study involving a cross-sectional field study with a quantitative approach, in which patients from the Dr. Adalberto Maternity Hospital in Anápolis, Goiás, were interviewed and clinically examined. Pregnant women from the first to ninth month of gestation who agreed to participate in the research, and signed the Free Informed Consent (FIC) form, were included. The study excluded diabetic pregnant women, those taking antibiotics or anti-inflammatory drugs, or presenting any other condition which could influence their periodontal condition.

The patients were individually approached on the day of their prenatal visit and signed the FIC form. They were instructed on oral hygiene techniques, a clinical examination was performed and the data recorded on a previously drawn up clinical record sheet. The clinical evaluations included the Periodontal Screening and Recording (PSR), bleeding on probing and tooth loss. The PSR code were classified according with Stefani et al. ${ }^{(11)}$. Material for these exams included the following instruments: mirrors, tweezers, WHO, Nabers and de Williams periodontal probes, cotton and gauze. The oral exams were performed in the dental office of the Division itself on a previously scheduled day and at the most convenient time for the pregnant women. The Gingival Index $(\mathrm{Gl})$ was calculated to evaluate gingival bleeding on the four dental surfaces after probing.

The data were tabulated in an Excel worksheet. Linear Regression Analysis was applied between the independent variables: gestation, brushing, flossing, smoking and the gingival index. The level of significance was set at $5 \%$. 


\section{RESULTS}

A total of 100 pregnant women with a mean age of 24.17 years, ranging from 14 to 40, participated in this study. In all, 2667 teeth were evaluated and an absence of $133(4.75 \%)$ was found. Third molars were excluded from this count.

Gestation time was divided into trimesters, being that the mostly of the pregnant woman were in third trimesters $(46 \%)$, whilst $39 \%$ in the second trimesters and $15 \%$ in the first trimester. In relation to the frequency of brushing, it can be seen that $55 \%$ brushed three times a day, while $35 \%$ brushed twice and $10 \%$ reported brushing more than three times a day. In terms of flossing, $49 \%$ reported doing so up to three times a day, while $48 \%$ reported once a day and $3 \%$ more than three times a day.

The results also showed that all sextants of the mouth (I, II, III, IV, V, VI) presented an average of $90 \%$ PSR Code 2 (ranging from 86 to $95 \%$ ) while Code 4 and Code $^{*}$ (mobility, furcation, gingival recession greater than or equal to $3 \mathrm{~mm}$ ) were not seen in any of the pregnant women's sextants. The other codes are shown in Table 1.

Table 1. Percentage of distribution of PSR codes by sextant.

\begin{tabular}{c|c|c|c|c|c|}
\hline Sextant & $\mathbf{0}$ & $\mathbf{1}$ & $\mathbf{2}$ & $\mathbf{3 f}$ & Total \\
\hline $\mathrm{I}$ & $0 \%$ & $2 \%$ & $89 \%$ & $9 \%$ & $100 \%$ \\
\hline $\mathrm{II}$ & $0 \%$ & $5 \%$ & $95 \%$ & $0 \%$ & $100 \%$ \\
\hline $\mathrm{III}$ & $0 \%$ & $2 \%$ & $87 \%$ & $11 \%$ & $100 \%$ \\
\hline $\mathrm{IV}$ & $0 \%$ & $1 \%$ & $86 \%$ & $13 \%$ & $100 \%$ \\
\hline $\mathrm{V}$ & $0 \%$ & $4 \%$ & $96 \%$ & $0 \%$ & $100 \%$ \\
\hline $\mathrm{VI}$ & $0 \%$ & $0 \%$ & $88 \%$ & $12 \%$ & $100 \%$ \\
\hline
\end{tabular}

As regards the $\mathrm{GI}$, an average of $12 \%$ bleeding, varying between 0 and $43 \%$, can be seen. Table 2 shows the areas with higher and lower occurrences of bleeding after probing, according to dental regions (anteriors, premolars and molars). When occurred the same quantitaty of dental faces bleeding, the areas were categorized: (anteriors, premolars and molars; anteriors and molars; premolars and molars). In Table 2 could be shown the in only $12 \%$ of pregnants was not occured any bleeding on probing. Of the 100 pregnant women evaluated, 93 were non-smokers, while seven smoked an average of 10 cigarettes/day.

Table 2. Dental groups showed greater bleeding during probing

\begin{tabular}{l|c|}
\hline Areas of bleeding & $\%$ \\
\hline - Anteriors, Premolars and Molars & $2 \%$ \\
\hline - Anteriors and Molars & $5 \%$ \\
\hline - Premolars & $6 \%$ \\
\hline -No bleeding & $12 \%$ \\
\hline - Anteriors & $19 \%$ \\
\hline - Premolars and Molars & $21 \%$ \\
\hline -Molars & $35 \%$ \\
\hline Total & $100 \%$ \\
\hline
\end{tabular}

The probing was performed using WHO probe.

Quantitative variables were also correlated with $\mathrm{Gl}$ and the results showed (Table 3 ) that there was no correlation with the variables evaluated $(p>0.05)$.

Table 3. Correlation between Gingival Index ( $\mathrm{Gl}$ ) and quantitative variables using Spearman test

\begin{tabular}{c|c|c|c|c|c|}
\cline { 3 - 6 } \multicolumn{2}{c|}{} & $\begin{array}{c}\text { Gestation } \\
\text { time }\end{array}$ & Smoking & Flossing & Brushing \\
\hline \multirow{4}{*}{$\mathrm{GI}$} & $\begin{array}{c}\text { Correlation } \\
\text { coefficient }\end{array}$ & 0.16 & 0.34 & -0.123 & -0.009 \\
\cline { 2 - 6 } & Significance* & 0.88 & 0.74 & 0.22 & 0.930 \\
\cline { 2 - 6 } & $\mathrm{N}$ & 100 & 100 & 100 & 100 \\
\hline
\end{tabular}

*Significance level: $p<0.05$.

\section{DISCUSSION}

Gingivitis can be considered the main oral disease affecting women in the gestational period, due to an increase in the concentration of female sex hormones, and leads to exacerbated gingival inflammation $(2,5,8,12)$.

A total of 100 pregnant women with a mean age of 24.17 years participated in this study. In all, 2667 teeth were evaluated. Of these $4.75 \%$ were absent (133 teeth), and the third molars were not considered. It was seen that most of the pregnant women (48\%) were between 21 and 30 years old, while the minority (19\%) were between 31 and 40 years. A study by Moimaz et al. ${ }^{(13)}$ presented a mean age of 24.7 years while that of Seraphim et al. ${ }^{(8)}$ presented a mean age of 26.18 years for the 96 pregnant women they evaluated. The mean ages in these studies were very close to those of this present study. However, in other studies, higher mean ages can be seen as in that of Monteiro et al. ${ }^{(14)}$ where it was 33 , while in that of Villa et al. ${ }^{(4)}$ who evaluated 750 pregnant women, it was 32 .

In terms of gestation, in the present study it can be seen that most $(46 \%)$ were in the third trimester, while in the study by Jeremias et al. ${ }^{(17)}$, involving 50 pregnant women, most, also $46 \%$, were in the second trimester of gestation. Monteiro et al. ${ }^{(13)}$ reported that the number of patients was the same in each trimester, and of the 75 pregnant women evaluated, about $33 \%$ were divided over each semester. A systematic review by Figuero et al. ${ }^{(15)}$ concluded that there was an exacerbation of gingivitis in the third trimester of pregnancy when compared to pregnant women in the first trimester. This increase could be explained by the gestational hormonal peak.

In this present study, the gingival indices $(\mathrm{GI})$ ranged from 0 to $43 \%$, with a mean of $12 \%$. It was seen that the area of greatest occurrence of bleeding $(35 \%)$ was in the molar region. Gingival bleeding was seen in about $88 \%$ of the pregnant women, while in $12 \%$ no bleeding was observed in any region. Other studies did not specify which regions presented greater bleeding; however, they presented the percentages of pregnant women who bled during the probing. In the study by Monteiro et al. ${ }^{(13)}$, bleeding occured in $38.6 \%$ of the 75 pregnant women evaluated. Moimaz et al. ${ }^{(16)}$ found that $67.06 \%$ of the pregnant women presented gingival bleeding. In another study by Moimaz et al. ${ }^{(13)}$ only $15 \%$ of the women presented bleeding. Jeremias et al. ${ }^{(17)}$ in their research presented lower results where only $10 \%$ presented gingival bleeding out of 50 patients. This high percentage of pregnant women presenting bleeding after probing $(88 \%)$ was probably due to the fact that they had received little or no guidance on oral hygiene, and that they were younger women (about one-third were under 20), and greater bleeding is common in younger women ${ }^{(18)}$. In addition, about $48 \%$ of the pregnant women reported not using dental floss during hygiene. Although the bleeding occurred in $88 \%$ of the women, the mean $\mathrm{GI}(12 \%)$ was relatively low and there was no correlation with the quantitative variables (smoking, using dental floss, brushing and gestation time) (Table 3).

As regards hygiene, 55\% reported brushing their teeth 3 times a day, while $35 \%$ brushed up to twice a day and $10 \%$ more than 3 times a day. And it can be noted that almost half (48\%) did not use dental floss. In a study by Silveira et al. ${ }^{(19)}$, it was seen that all the pregnant women brushed their teeth, the majority $(63.3 \%)$ three times a day, while only $30 \%$ used dental floss. In the study by Monteiro et al. ${ }^{(13)}$, it was seen that $34.6 \%$ reported brushing their teeth twice a day, $17.3 \%$ did not use dental floss, while $26.6 \%$ used floss in all brushings.

In the present study, the periodontal evaluation also used the PSR (Basic Periodontal Assessment) criteria, while using the WHO periodontal probe. Of the codes found in all sextants, $90 \%$ of the women presented Code 2, while Code * was not seen in any of the subjects. However, different results were found in a study by Rocha et al. ${ }^{(20)}$, in which $61.65 \%$ of the patients presented Code 1 , while only $23.31 \%$ presented Code 2. In a study by Rosell et al. ${ }^{(21)}$ involving 41 pregnant women, the highest prevalence was of Code 2, found in $56.1 \%$ of pregnant women, as in the present study. It should be noted that Code 2 refers to plaque retention factors. Thus, in the present study the vast majority had plaque retention agents, irrespective of whether or not bleeding was present. In view of the considerable presence of Code 2 , pregnant women should be more aware of the need to seek dental treatment more frequently, to reduce plaque retention agents and thereby have better control of the biofilm. This reduces the possibility of periodontal disease, and prevents the development of caries.

This study concluded that most pregnant women were in the third trimester of gestation, with a high prevalence of gingivitis, while no case of periodontitis was found. Most pregnant women reported brushing their teeth three times a day and flossing daily. 


\section{ACKNOWLEDGEMENTS}

We thank the financial support of the National Foundation for the Development of Higher Education (FUNADESP), and in particular, the cooperation of the pregnant women who readily became available to cooperate with the research project in question.

\section{CONFLICTS OF INTEREST.}

There are no confllicts of interest.

\section{References}

1. Chung LH, Gregorich SE, Armitage GC, Gonzalez-Vargas J, Adams SH. Sociodemographic disparities and behavioral factors in clinical oral health status during pregnancy. Community Dent Oral Epidemiol. 2014;42(2):151-9.

2. Ramos-e-Silva M, Martins NR, Kroumpouzos G. Oral and vulvovaginal changes in pregnancy. Clin Dermatol. 2016;34:353-8.

3. Cruz SS, Costa MCN, Gomes Filho IS, Vianna MIP, Santos CT. Materna periodontal disease as a factor associated with low birth weight. Rev Saúde Pública. 2005;39(5):782-7

4. Villa A, Abati S, Pileri P, Calabrese S, Capobianco G, Strohmenger L et al. Oral health and oral disease in pregnancy: a multicentre survey of Italian postpartum women. Aust Dent J. 2013;58:224-9.

5. Wu M, Chen SW, Jiang SY. Relationship between gingival inflammation and pregnancy. Mediators Inflamm. 2015;2015:623427.

6. Aarestrup BJV, Sales LAR, Aarestrup FM. Periodontal disease: natural history and influence of pregnancy: literature review. Bol Centr Biol Reprod. 2008;27(1/2):41-47. 7. Vogt M, Sallum AW, Cecatti JG, Morais SS. Factors associated with the prevalence of periodontal disease in low-risk pregnant women. Reprod Health. 2012;9(3):1-8.

8. Seraphim APCG, Chiba FY, Pereira RF, Mattera MSLC, Moimaz SAS, Sumida $\mathrm{DH}$. Relationship among periodontal disease, insulin resistance, salivary cortisol and stress levels during pregnancy. Braz Dent J. 2016;27(2):123-27.

9. Huck O, Tenenbaum H, Davideau J. Relationship between periodontal diseases and preterm birth: Recent epidemilogical and biological data. J Pregnancy. 2011;11(2):1-8.

10. Zanatta FB, Machado E, Zanatta GB, Fiorini T. Maternal periodontal disease and premature and low birth weight: a critical review of current evidence. Arq Catarin de Med. 2007;36(1):96-102

11. Stefani CM, Rodrigues IFG, Façanha CP, Pereira SLS, Salum EA, Notici Júnior $\mathrm{FH}$. Evaluation of the periodontal treatment needs and the root caries index in population of Fortaleza-CE. Rev. Odontol. UNESP. 2003;32(1):61-66.
12. Geinsiger ML, Geurs NC, Bain JL, Kaur M, Vassilopoulos PJ, Cliver SP et al. Oral health education and therapy reduces gingivitis during pregnancy. J Clin Periodontol. 2014;41:141-48.

13. Moimaz SAS, Carmo MP, Zina LG, Saliba NA. Association between the periodontal condition of pregnant women and maternal variables and health assistance. Pesq Bras Odontoped Clin Integr. 2010;10(2):271-278.

14. Monteiro RM, Scherma AP, Aquino DR, Oliveira RV, Mariotto AH. Evaluation of pregnants oral hygiene habits by quarter. Braz J Periodontol. 2012; 22 (4): 90-99. 15. Figuero E, Carrillo-de-Albornoz A, Martín C, Tobías A, Herrera D. Effect of pregnancy on gingival inflammation in systematically healthy women: a systematic review. J Clin Periodontol. 2013:40:457-73

16. Moimaz SAS, Garbin CAS, Saliba NA, Zina LG. Periodontal status during pregnancy in a group of Brazilian women. Cienc Odontol Bras. 2006;9(4):59-66

17. Jeremias F, Silva SRC, Valsecki Junior A, Tagliaferro EPS, Rosell FL. Selfperception and oral health status in pregnant women. Odontol Clín Cient. 2010;9(4):359-363.

18. Khosravisamani M, Malliji G, Seyfi S, Azadmehr A, Abd Nikfarjam B, Madadi S et al. Effect of the menstrual cycle on inflammatory cytokines in the periodontium. Periodontal Res. 2014;49(6):770-6.

19. Silveira RCJ, Amaro CJ, Souza EHA. Conditions evaluation of higiene and oral health in pregnant women. Rev Cons Reg Odontol. 2000;3(2):61-70.

20. Rocha BM, Fortes TMV, Novais SMA, Santana MJ. Study of the peridontal conditions in pregnant patients by the PSR and prevalence of pre-term low birth weight babies. Periodontia. 2004;14(3):42-46.

21. Rosell FL, Montadon Pompeu AAB, Valsecki Junior A. Periodontal screening and recording in pregnant women. Rev. Saúde Pública. 1999;33(2):157- 62. 